DOI: https://doi.org/10.32839/2304-5809/2020-11-87-19

UDC 378.147.227

Harashchenko Larysa, Kondratiuk Svitlana

Pedagogical Institute, Borys Grinchenko Kyiv University

Kondratiuk Andrii

National Economic University named after Vadym Hetman

\title{
HOW TO FORM VALUE RELATION TO HEALTH IN FUTURE PEDAGOGUES
}

Summary. The article looks at basic formation mechanisms for value health relation in future pedagogues. It considers the necessity of pedagogues' conscious and value relation to the issue of children's health establishment. Effectiveness of implementing various physical education and health means into the educational process depends on prioritizing health supporting activities, appropriate application of various physical education and health means. Basic forming mechanism of future pedagogues' value relation to health is defined as student's learning activity activation. The article defines tasks of future pedagogues' value relation to health. Important condition of students' learning activity organization is practical and professional focus of different organizational study forms, students' self-working, creative projects etc., provided by a professor. Students' qualitative professional preparation is generally defined by organization of research and experimental educational and learning activity. The article proves importance of using business and role-play, analytical and constructional tasks (pedagogical situations), discussions, which help students gain their own pedagogical experience. An important condition in students' forming value relation to health issue is defined as psychological and pedagogical support in self-development and self-establishment process.

Key words: health preserving activity, educational and learning activity, interactive forms of relations, activity component in professional preparation.

Гаращенко Л.В., Кондратюк С.Г. Педагогічний інститут Київського університету імені Бориса Грінченка

Кондратюк А.Г.

Національний економічний університет імені Вадима Гетьмана

\section{ШЛЯХИ ФОРМУВАННЯ У МАЙБУТНІХ ВИХОВАТЕЛІВ ЦІННІСНОГО СТАВЛЕННЯ ДО ЗДОРОВ'Я}

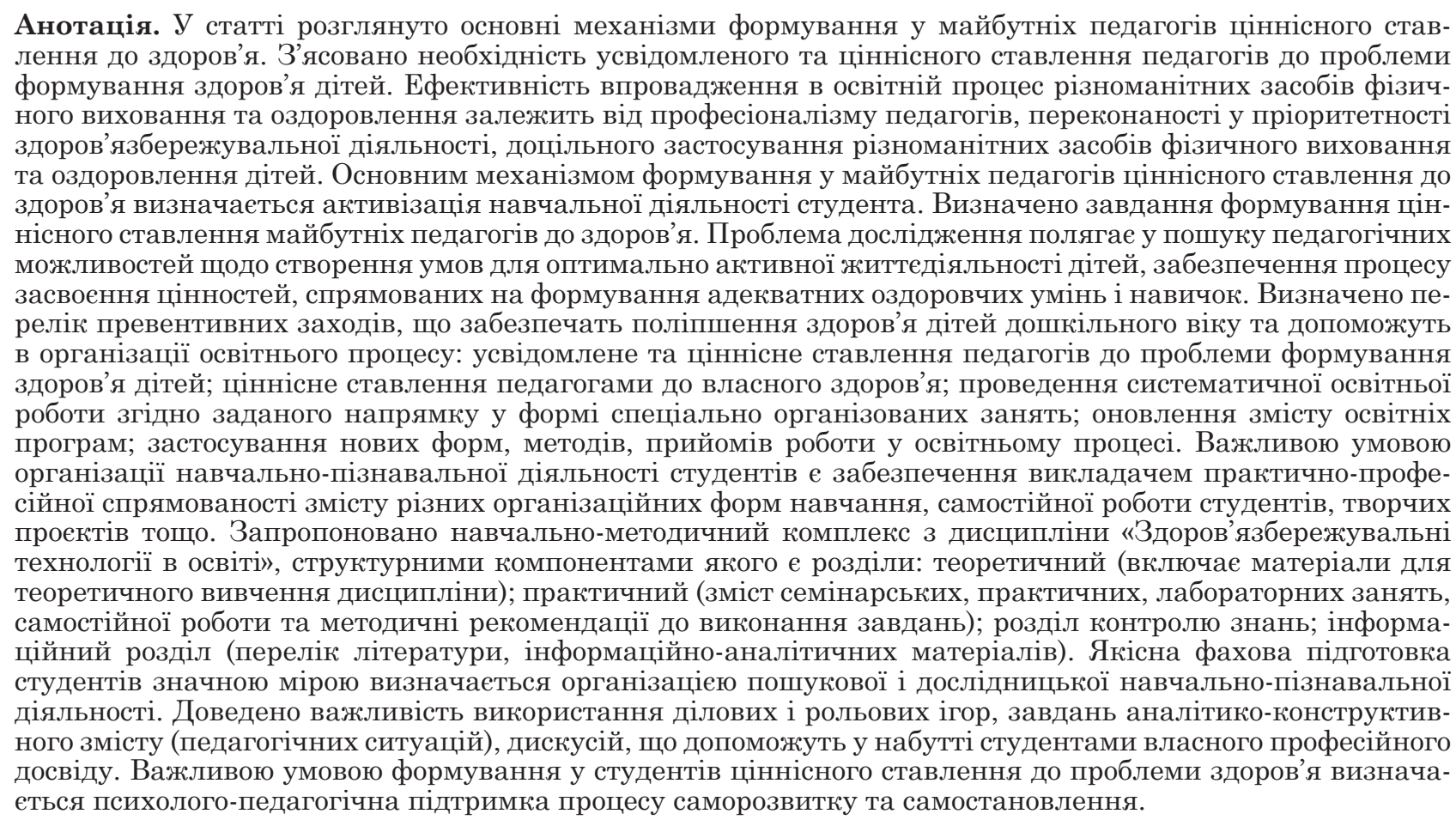

Ключові слова: здоров'язбережувальна діяльність, навчально-пізнавальна діяльність, інтерактивні форми взаємодії, діяльнісний компонент фрахової підготовки.

Droblem setting. Actuality of children's health preservation, strengthening and forming is enforced by socio economical and socio cultural situation in the modern society, when it is necessary to find out, how to implement health preservation process in young generation depending on real living conditions. Negative trend in health worsening is caused by life level decrease, social shocks, ecological aggravation, public healthcare decrease, and influence of stress generating 
modern social environment [10]. Now, we observe some progress in health preservation, achieved during XX century. However, in modern conditions, humanity faces new problems, which are a danger to global safety, and which should be opposed by healthcare systems [9]. Pre-school children health analysis led to main health weakening causes and their development rates, taking into account that above factors influence children most during their intensive growing period, forming all the organs and systems, and also due to their complex, prolonged impact on child's susceptible organism. Pre-school children health weakening issues lead to critical need of preventive means in educational process organization. At first, it means conscious and value pedagogues' relation to children health forming issue. Research issue is looking for pedagogical possibilities to creating conditions to optimal active children activities, providing values acknowledgement process, focused on adequate wellness skills forming. Efficacy of various physical educational means implementing into educational process depends on pedagogues' proficiency, preschool education institution health preserving activity inner efficiency-raising sources mobilization. So, the issue of future pedagogues' value relation to health forming is gaining actuality.

Scientific researches prove health preservation essence of educational process, which provisions organizing all life activities processes according to educational process organization regularities, effectiveness of means and ways of educational effect on children, taking into account their needs, interests, personal characteristics and potential abilities $[5 ; 8]$.We should note that scientists consider the issue of leading role of person in preservation, enforcing and forming health, even taking into account various environment factors $[2 ; 3]$. We fully agree with the authors on importance of personal activities and social institutions in health preservation. Review of scientific researches on preschool children health issues reasons to state that main basis for all the health kinds is physical. That is why $\mathrm{O}$. Bohinich says that caretakers have the task of the most optimal means of education and teaching children in order to improve their physical development, because foundations for health are set in preschool age. Her research proves that a child can realize his or her age possibilities as well as organism possibilities to the full if provided self-activity and conditions for his or her complete, active, happy growing [4]. As for now, it is crucial to create motivation in a healthy individual, starting from preschool age.

The purpose of the study is to determine the main mechanisms of formation of future teachers' values of health.

The research focuses at defining basic mechanisms of forming value relation to health in future pedagogues.

Based on the position of physical and mental (intellectual and emotional) health unity, we believe, that one of the main aspects in health preservation practice is child's immersion in health preserving environment at the preschool institution, centered at a pedagogue. It provides presence of one's own health preservation position, which reflects mastering of practical actions means, taking daily optimal motivated solutions, aimed at adequate wellness behavior, turning health and physical education values into personal achievements through thorough activities $[1 ; 5 ; 6 ; 7]$. We consider physical culture as a condition and active component of preserving and forming child's health. Physical culture trainings promote growth of adaptive reserve in child's organism and increase its resistance to negative affect of the environment. That is why fundamental part in professional training process belongs to future pedagogues' readiness to solve physical education and wellness issues. Based on dynamical changes in approaches and realization of future pedagogues' value relation to health forming process, we explore main reasons, which make this issue drastic.

The following are important tasks in future pedagogues' value relation to health forming:

- Acknowledgement of health value and readiness to realize in practice wellness paradigm in one's own professional activity;

- Viewpoint rethinking of physical culture and wellness direction prioritizing in preschool education system; presence of subjective health preserving position;

- Mastering system of experience, health preserving skills, focused on sticking to requirements of leading healthy lifestyle and adequate wellness behavior;

- Skill of creative and mobile realizing practical skills to provide preconditions of preserving and forming children's health and responsible attitude to one's own professional development as a continuous process.

Let's look at O. Bohinich works, theoretical analysis of which enables to say that modern society development requires 'innovative learning', which would form in students ability to projective determining the future, responsibility for it, self-belief and belief in professional abilities. The author underlines changes in education organization approaches: Prioritizing active learning and skills based on creative interaction between professor and students, the idea of personally oriented preparation of future pedagogues [4].

First, it is working learning programs contents renewal, including course methods of physical education for preschool children. This subject has to change modern preschool education relation to a child, which presupposes conditions for optimal active lifestyle with high health level.

It seems appropriate to reflect such questions in separate modules and topics of the course: Forming professional activity motivation, forms of work on regular physical exercises need development, implementing the principle of prioritizing physical culture and wellness work with children; strong knowledge of factors which affect health; anatomical, physiological and psychological features of preschool children; rules of growth and physical development of children; morphological and functional support of movement activities for the children; need to organize health preserving environment in the preschool educational institution, and providing health preserving children physical education way; monitoring health and physical preparedness level of the children; health preserving essence of educational process in preschool education institution etc. 
It is appropriate to accent the activation of student's learning activity to form value relation to health issue in future pedagogues. To make each student interested in cognitive process might be appropriate teaching and methodological complex of subject Methods of physical education for preschool children, structural components of which should be scientific experimental tasks. It is important to make students interested in scientific work, raise their emotions, inspire them with local research topic, and activate creative thought. Besides, while performing experimental work, students develop their practical skills and work out their methodological approach. Realization of learning and methodical subject complex presupposes reinforcement of professional, practical, problematical and research direction of professional preparation, as well as students' self-work activation. Professional and practical direction in contents of self-assessment tasks serves as a basis for student's personal methodical findings realization during pedagogical practice.

Appropriate pedagogical instruments of forming value relation to health issue in future pedagogues are: problem learning; video lectures development; conducting practical lessons on preschool education institution basis; using nontraditional technologies in conducting physical wellness events (morning exercises, physical culture break, open air trainings etc.) during practical lessons in form role and business play; involving students to discussing various issues during practical lessons in form of round tables; mini-projects development during pedagogical practice and so on. For students' personal motivation it would be appropriate different difficulty level tasks, which students can perform on their choice.

To enforce students' value relation to health preservation and forming issue, it is not only important to master the system of skills and competencies in the field of physical wellness work with children, but also recognition of objective and subjective reasons for health forming need. On background of abrupt changes in the society there arises a need to analyze dynamical changes in the social world. It means that social and economic changes in the world, caused by COVID-19 spread, lead to necessity of creating adequate social and pedagogical conditions. In terms of distance learning it is crucial to realize skills and competencies for health forming in creative, flexible and fast way. While organizing learning process through electronic educational courses, online teaching etc., it is appropriate to improve lessons contents and rethink self-tasks for students. So far, it is necessary to use video lectures. At these lectures, professor should not only present information, but also serve as health preserving actions example. Students' tasks should have practical direction. For example, they might make a video clip, where a student has to present (show and explain) how he or she performs physical exercises (for posture and feet, breathing exercises, finger exercises etc.) which can be done

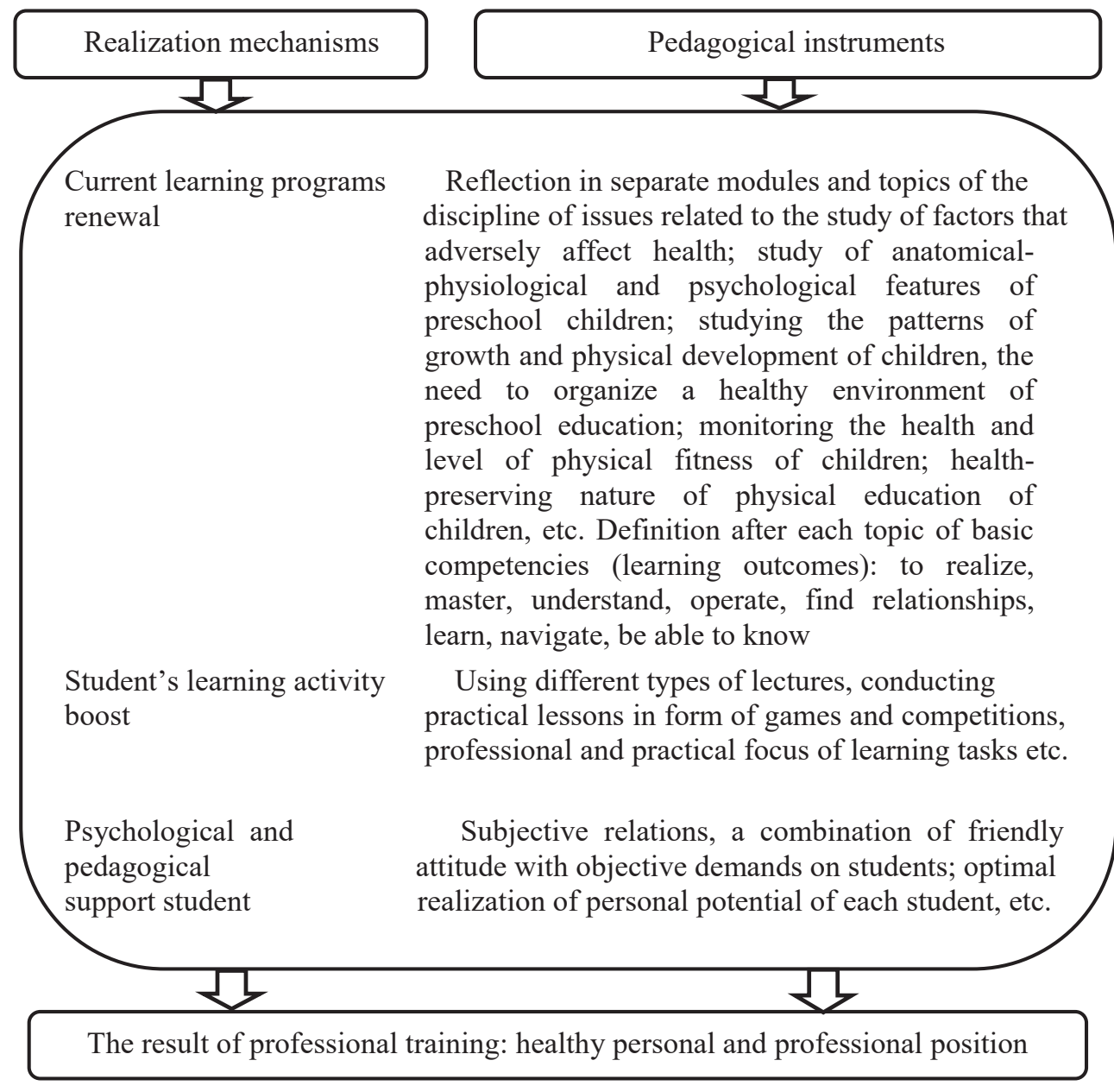

Figure 1. Mechanisms and pedagogical instruments of forming students' value relation to health 
at home, on limited space and without any sport appliances. Students might be proposed to make interesting stories for children about sport appliances, wellness means, healthy food, laughter, laziness, movement activities, bad habits etc. and present it in a video. Such tasks boost student's search activity; contribute to physical activity, as well as his or her work value. Such tasks activate the student's search activity, will help to increase motor activity, as well as the importance of his work. Students can use the results of their own work during pedagogical practice in preschool institutions.

An important condition of forming students' health issue value relation is psychological and pedagogical support in process of self-development and self-establishment. Such support means humane relation to students, flexible orientation of professor due to process and results of reproductive, research, learning activities and student's personal achievement. Above material is represented graphically in mechanisms and pedagogical instruments of forming students' value relation to health (Figure 1).

Conclusions. Conscious and value relation of future professionals to children health forming issue, readiness to learn a child, development situation, to choose education contents significant for this process, readiness to provide conditions to preserve and enforce children's health are the priorities of health preserving activity, which correspond to requirements of parents, caretakers and modern trends in preschool education development. Future caretaker should be able to provide for a child a possibility to choose self-valuable for her or him types of children activity and help a child to gain personal health preserving experience (wellness solutions, wellness behavior skills etc.). In turn, it leads to change in pedagogical instruments of professional training. Thus, an important condition in organizing students' learning activity is to provide by a professor practical and professional direction in contents of various learning forms, students' selftasks, creative projects etc. Qualitative professional training of students mostly depends on research learning activity organization, using business and role play, specific pedagogical situations, discussions, trainings, which can help students gain their own professional experience.

So, as a result of professional training should be a pedagogue with clear motivation and a need to master professional experience in the field of preserving and enforcing preschool children's health. Realization of active component in professional training presupposes personal interest of a student in personal professional development. Such approach provides that future preschool education professionals would have personal professional health forming position.

The prospect of further exploration is to develop a model of the system of preparing students for physical culture and health work with preschool children.

\section{References:}

1. Andriushchenko, T.K. (2012). Formation of health-saving competence as a socio-pedagogical problem. Scientific Bulletin of the Volyn National University named after Lesia Ukrainka, 7, 123-127.

2. Bielenka, H.V., Bohinich, O.L., \& Mashovets, M.A. (2006). Child's health - from the family. Kyiv: SPD Bohdanova A. M.

3. Bobrytska, V.I. (2006). Theoretical and methodological bases of formation of healthy way of life for future teachers in the process of science study. Institute of Pedagogy and Psychology of Vocational Education Academy of Educational Sciences of Ukraine. Kyiv.

4. Bohinich, O. (2007). Main mechanisms for improving the system of training specialists in preschool education, Bulletin of the Hlukhiv State Pedagogical University. Series: Pedagogical Sciences, 9, 10-16.

5. Bohinich, O. (2010). Priorities in the field of physical development of a child of preschool age, Optimization of the child's physical development in the domestic education system: a monograph (124-148). Zaporizhzhia: Zaporizhzhya Regional Institute of Postgraduate Teacher Education.

6. Harashchenko, L.V. (2014). The development of the healthcare idea in physical education of children in preschools in Ukraine (the second half of XX - the beginning of the XXI century). Borys Grinchenko Kyiv University. Kyiv.

7. Kondratiuk, S.G. (2018). Psychodidactic determinants of the development of children of preschool age. Wiadomości lekarskie, 71(6), 1207-1214.

8. Lisnevska, N.V. (2016). Pedagogical conditions for creating a healthy environment in a preschool institution. Institute of Education Problems the National Academy of Educational Sciences of Ukraine. Kyiv.

9. Moskalenko, V.F. (2010). Urbanization and health: a global problem today. Eastern European Journal of Public Health, 1, 9-19.

10. Suvi Määttä, Reetta Lehto, Mari Nislin, Carola Ray, Maijaliisa Erkkola, Nina Sajaniemi, Eva Roos \& on the behalf of the DAGIS research group (2015). Increased health and well-being in preschools (DAGIS): rationale and design for a randomized controlled trial. BMC Public Health, 15: 402. 